Conclusion: More than one third of patients with $A U$ fulfilled the criteria for axial or peripheral SpA. Furthermore, the prevalence of back pain, increased BASDAI and serum CRP levels was significantly higher in AU patients with $S p A$ compared to non-SpA subjects and HC. Inflammatory back pain was significantly more often in patients with $A U$ classified as axSpA. Patients with hsBME had significantly higher serum CRP levels compared to the rest of the patients.

Acknowledgement: Supported by MH CR 023728, SVV 260373, AZV 17-33127A

Disclosure of Interests: Kristýna Bubová: None declared, Monika Gregová: None declared, Kateřina Zegzulková: None declared, Karel Pavelka: None declared, Jarmila Heissigerová: None declared, Ladislav Šenolt Grant/ research support from: AbbVie, Consultant for: AbbVie, Bristol-Myers Squibb, Celgene Corporation, Merck Sharp and Dohme, Novartis, Pfizer, Roche, UCB, Amgen, Takeda, Speakers bureau: AbbVie, Amgen, BristolMyers Squibb, Celgene Corporation, Eli Lilly, Merck Sharp and Dohme, Novartis, Pfizer, Roche, UCB

DOI: 10.1136/annrheumdis-2019-eular.7439

\section{THU0374 GENDER DIFFERENCE IN ASAS HEALTH INDEX IN PATIENTS WITH ANKYLOSING SPONDYLITIS}

Hsin-Hua Chen ${ }^{1,2}$, Ting-I Pan ${ }^{3}$, Yi-Ming Chen ${ }^{2}$, Kuo-Lung Lai ${ }^{2}$, Tsu-Yi Hsieh ${ }^{4}$, Ching-Tsai Lin ${ }^{2}$, Wei-Ting Hung ${ }^{4}$, Yin-Yi Chou ${ }^{2}$, Chih-Wei Tseng ${ }^{2}, Y_{i}-D a ~ W{ }^{2}$, Chia-Wei Hsieh", Wen-Nan Huang ${ }^{2}$, Yi-Hsing Chen ${ }^{2}$, Der-Yuan Chen ${ }^{5} .{ }^{1}$ Taichung Veterans General Hospital, Department of Medical Research, Taichung, Taiwan, Republic of China; ${ }^{2}$ Taichung Veterans General Hospital, Division of Allergy, Immunology and Rheumatology, Department of Internal Medicine, Taichung, Taiwan, Republic of China; ${ }^{3}$ Tunghai University, Department of Industrial Engineering and Enterprise Information, Taichung, Afghanistan; ${ }^{4}$ Taichung Veterans General Hospital, Department of Medical Education, Taichung, Taiwan, Republic of China; ${ }^{5}$ China Medical University Hospital, Rheumatology and Immunology Center, Taichung, Taiwan, Republic of China

Background: The Assessment of Spondyloarthritis international Society Health Index (ASAS HI) has been develop and validated to assess health and function in patients with spondyloarthritis. However, whether ASAS HI differs between men and women is unknown. The aim of this study was to compare ASAS $\mathrm{HI}$ between men ans women in patients with ankylosing spondylitis (AS).

Objectives: The aim of this study was to compare ASAS $\mathrm{HI}$ between men ans women in patients with ankylosing spondylitis (AS)

Methods: Since November 2016, we measured and recorded data of demography, comorbidity, family history, medication use, the Ankylosing Spondylitis Disease Activity Score (ASDAS), the Bath Ankylosing Spondylitis Disease Activity Index (BASDAI), the Bath Ankylosing Spondylitis Functional Index (BASFI), the modified Stoke Ankylosing Spondylitis Spinal Score (mSASSS) and the ASAS HI for AS patients in clinical practice using an electronic patient reported data system linked to an electronic medical record system in Taichung Veterans General hospital (TCVGH). We retrieved the last recorded data of AS patients in TCVGH during 2017/11-2018/10. We assessed the association between gender and the ASAS $\mathrm{HI}$ using a multivariable linear regression model. Variables from the univariable linear regression analysis with $p<0.2$ were included in then multivariable analysis. We used a forward selection method to build the models.

Results: A total of 307 AS patients [62 (20.2\%) females, mean age 46.4 years (S.D. 13.3), mean symptom duration 20.6 years (S.D. 12.1)] were included. Female patients had an older age at onset $(29.2 \pm 12.6$ vs $24.9 \pm 9.6$ years, $p=0.015)$, a shorter symptom duration $(15.7 \pm 11.6$ vs $21.8 \pm 12.0$ years, $p<0.001)$, a lower proportion of smoking $(6.5 \%$ vs $48.2 \%, p<0.001)$, higher ASAS $\mathrm{HI}(5.9 \pm 3.8$ vs $4.3 \pm 3.4, \mathrm{p}=$ $0.001)$, higher ASDAS-ESR $(1.9 \pm 0.8$ vs $1.5 \pm 0.8, p<0.001)$ and lower mSASSS $(6.0 \pm 11.4$ vs $21.8 \pm 23.1, p<0.001)$ than male patients. There were no significant differences in BASFI $(1.1 \pm 1.6$ vs. $1.2 \pm 1.7, p=0.765)$, ASDAS-CRP $(1.5 \pm 0.9$ vs. $1.5 \pm 0.9, p=0.972)$ and BASDAl $(2.4 \pm 1.8$ vs. $2.0 \pm 1.4, p=0.115)$ between females and males. In multivariable analysis, male gender was significantly associated with a better ASAS $\mathrm{HI}(B=-1.73,95 \% \mathrm{Cl}:-2.55,-0.91, \mathrm{p}<0.001)$. Other significant predictors of ASAS $\mathrm{HI}$ included BASDAI $(B=1.29,95 \%$ $\mathrm{Cl}: 1.07,1.50, \mathrm{p}<0.001)$, disease duration $(B=0.04,95 \% \mathrm{Cl}: 0.01$, $0.06, p=0.015)$, mSASSS $(B=0.02,95 \% \mathrm{Cl}: 0.01,0.04, p=0.003)$ and hepatitis $\mathrm{B}(B=0.99,95 \% \mathrm{Cl}: 0.03,1.96, \mathrm{p}=0.044)$.

Conclusion: This single center, cross-sectional study revealed that male gender was significantly associated with lower ASAS HI in AS patients.

\section{REFERENCE:}

[1] Kiltz U, van der Heijde D, Boonen A, Akkoc N, Bautista-Molano W, et al. 2018. Measurement properties of the ASAS Health Index: results of a global study in patients with axial and peripheral spondyloarthritis. Annals of the rheumatic diseases $77: 1311-7$.

Disclosure of Interests: Hsin-Hua Chen Speakers bureau: Johnson \& Johnson, Novartis, Pfizer, Abbvie, Roche, UCB, Bristol-Myers Squibb, Chugai, Ting-I Pan: None declared, Yi-Ming Chen Grant/research support from: GSK, Pfizer, BMS, Astra \& Zeneca, Consultant for: Pfizer, Novartis Abbvie, Johnson \& Johnson, BMS, Roche, Sanofi, MSD, Guigai, Astellas Inova Diagnostics, UCB Agnitio Science Technology, United Biopharma Thermo Fisher, Paid instructor for: Pfizer, Novartis, Abbvie, Johnson \& Johnson, BMS, Roche, Astra\& Zeneca, Sanofi, MSD, Guigai, Astellas UCB Thermo Fisher, Speakers bureau: Pfizer, Novartis, Abbvie, Johnson \& Johnson, BMS, Roche, Lilly, GSK, Astra\& Zeneca, Sanofi, MSD, Guigai, Astellas UCB Thermo Fisher, Kuo-Lung Lai: None declared, Tsu-Y Hsieh: None declared, Ching-Tsai Lin: None declared, Wei-Ting Hung None declared, Yin-Yi Chou: None declared, Chih-Wei Tseng: None declared, Yi-Da Wu: None declared, Chia-Wei Hsieh: None declared Wen-Nan Huang: None declared, Yi-Hsing Chen: None declared, DerYuan Chen: None declared DOI: 10.1136/annrheumdis-2019-eular.5733

\section{THU0375 CLINICAL FEATURES OF AXIAL SPONDYLOARTHRITIS PATIENTS DIAGNOSED IN PERIPHERAL VERSUS AN ACADEMIC HOSPITAL}

Ann-Sophie De Craemer $^{1,2}$, Thomas Renson ${ }^{1,2}$, Philippe Carron ${ }^{1,2}$ Peggy Jacques $^{1,2}$, Jan Lenaerts ${ }^{3,4}$, Lieve Gyselbrecht ${ }^{5}$, Rik Joos ${ }^{1,6}$, Filip van den Bosch ${ }^{1,2}$, Dirk Elewaut ${ }^{1,2}$, Be-Giant consortium. ${ }^{1}$ Ghent University Hospital, Ghent, Belgium; ${ }^{2}$ VIB Inflammation Research Center, Ghent, Belgium; ${ }^{3}$ Reuma Instituut, Hasselt, Belgium; ${ }^{4}$ University Hospital Gasthuisberg, Leuven, Belgium; ${ }^{5}$ Algemeen Stedelijk Ziekenhuis, Aalst, Belgium; ${ }^{6}$ ZNA Jan Palfijn, Merksem, Belgium

Background: Diagnosis of axial spondyloarthritis $(\mathrm{axSpA})$ often relies on a positive magnetic resonance image of the sacroiliac joints (MRI-SIJ). However, pitfalls in interpretation of MRI-SIJ were recently acknowledged (1). Thus reader's expertise might be a source of heterogeneity in patient populations diagnosed with non-radiographic axSpA.

Objectives: We compared clinical characteristics of axSpA patients diag nosed in peripheral hospitals (MRI evaluation by local experts) versus an academic hospital (MRI central reading by trained radiologists and rheumatologists).

Methods: Patients originate from the Be-Giant cohort, a Belgian nationwide observational registry of axSpA patients diagnosed by expert opin ion. Included patients fulfill the Assessment of SpondyloArthritis international Society (ASAS) classification criteria for $\mathrm{axSpA}$ and are antiTNF- $\alpha$ naïve prior to inclusion. Patient enrollment started in 2010 and 2012 at the outpatient clinic of 1 academic and 7 peripheral hospitals respectively. Patients were free to visit a rheumatologist of their choice without necessity for referral by a general practitioner.

Results: By January 2019, 291 axSpA patients were included. Table 1 presents demographic and clinical characteristics according to the diag nostic echelon. The patient fraction fulfilling the imaging arm of the ASAS classification criteria was similar in both settings $(75,4 \%$ vs. $88,7 \%$, $p=0,21)$. However, because of a higher HLA B27 positivity rate in patients diagnosed in an academic versus peripheral hospitals $(73,5 \%$ vs $57,4 \%, p=0,01)$, a significantly higher fraction of patients fulfilled both the clinical and imaging arm in the former diagnostic setting $(63,0 \%$ vs. $37,7 \%, p=0,01)$.

Conclusion: Patients diagnosed with axSpA in peripheral versus an academic hospital generally show similar demographic and clinical characteristics. In an academic center, patients diagnosed with axSpA are more likely to be HLA B27 positive and to fulfill both ASAS classification arms indicating that rheumatologists in peripheral hospitals seem to assign more value to MRI findings compared to HLA B27 status in the diagnos tic process.

\section{REFERENCES:}

[1] Varkas G, de Hooge M, Renson T, De Mits S, Carron P, Jacques P, et al. Effect of mechanical stress on magnetic resonance imaging of the sacroiliac joints: assessment of military recruits by magnetic resonance imaging study. Rheumatology (Oxford). 2018;57(3):508-13. 
Abstract THU0375 - Table 1

\begin{tabular}{lccc}
\hline & $\begin{array}{c}\text { Peripheral } \\
\text { center } \\
(\mathbf{n}=\mathbf{6 1})\end{array}$ & $\begin{array}{c}\text { Academic } \\
\text { center } \\
\mathbf{( n = 2 3 0 )}\end{array}$ & $\begin{array}{c}\mathbf{p}- \\
\text { value }\end{array}$ \\
\hline Age at diagnosis (years) & $33,6(9,23)$ & $31,3(9,01)$ & 0,08 \\
Male gender & $20(32,8)$ & $118(51,3)$ & $\mathbf{0 , 0 1}$ \\
HLA B27 positivity & $35(57,4)$ & $169(73,5)$ & $\mathbf{0 , 0 1}$ \\
Symptom duration at diagnosis (years) & $4,8(5,45)$ & $4,2(5,60)$ & 0,51 \\
ASAS classification criteria imaging & $46(75,4)$ & $204(88,7)$ & 0,21 \\
arm & & & \\
ASAS classification criteria clinical arm & $35(57,4)$ & $169(73,5)$ & $\mathbf{0 , 0 1}$ \\
ASAS classification criteria both arms & $23(37,7)$ & $145(63,0)$ & $\mathbf{0 , 0 1}$ \\
Arthritis & $11(18,0)$ & $39(17,0)$ & 0,99 \\
Dactylitis & $1(1,6)$ & $7(3,1)$ & 0,88 \\
Enthesitis & $11(18,0)$ & $28(12,2)$ & 0,33 \\
Psoriasis & $7(11,5)$ & $20(8,7)$ & 0,68 \\
Inflammatory bowel disease & $3(4,9)$ & $14(6,1)$ & 0,87 \\
Acute anterior uveitis & $6(9,8)$ & $32(13,9)$ & 0,53 \\
BMI (kg/m²) & $23,8(3,86)$ & $24,4(4,02)$ & 0,26 \\
BASMI & $1,1(1,13)$ & $1,3(1,17)$ & 0,33 \\
MASES + fascia plantaris (/15) & $1,4(2,50)$ & $0,9(1,54)$ & 0,69 \\
BASDAI (/100) & $46(19,3)$ & $43(20,2)$ & 0,31 \\
BASFI (/100) & $30(22,5)$ & $28(21,8)$ & 0,77 \\
ASDAS - CRP & $2,43(0,89)$ & $2,47(0,93)$ & 0,80 \\
\hline
\end{tabular}

Continuous variables: mean (SD); other: counts(\%).

Disclosure of Interests: Ann-Sophie De Craemer: None declared, Thomas Renson: None declared, Philippe Carron: None declared, Peggy Jacques: None declared, Jan Lenaerts: None declared, Lieve Gyselbrecht: None declared, Rik Joos: None declared, Filip van den Bosch Consultant for: AbbVie, BMS, Galapagos, Janssen, Lilly, Merck, Novartis, Pfizer and UCB, Speakers bureau: AbbVie, BMS, Janssen, Lilly, Merck, Novartis, Pfizer and UCB., Dirk Elewaut: None declared

DOI: 10.1136/annrheumdis-2019-eular.2467

\section{THU0376 THE VALUE OF SACROILIAC JOINT RADIOGRAPHS IN THE EARLY SPONDYLOARTHRITIS ESPERANZA COHORT}

Eugenio de Miguel ${ }^{1}$, Beatriz Joven-lbáñez ${ }^{2}$, Eva Galindez ${ }^{3}$, Claudia UrregoLaurín $^{4}$, Maria Luz García-Vivar ${ }^{3}$, Cristina Fernández-Carballido ${ }^{5}$, Jose Francisco Garcia Llorente ${ }^{6}$, María del Carmen Castro Villegas ${ }^{7}$, Carolina Tornero ${ }^{1}$, Xavier Juanola-Roura ${ }^{8}$, Esperanza Working Group. ' $\mathrm{La}$ Paz University Hospital, Rheumatology, Madrid, Spain; ${ }^{2} 12$ de Octubre University Hospital, Madrid, Spain; ${ }^{3}$ Basurto University Hospital, Rheumatology, Bilbao, Spain; ${ }^{4}$ Moncloa University Hospital, Madrid, Spain; ${ }^{5}$ San Juan University Hospital, Rheumatology, Alicante, Spain; ${ }^{6}$ Galdakao University Hospital, Rhematology, Billbao, Spain; ${ }^{7}$ Reina Sofía University Hospital, Rheumatology, Córdoba, Spain; ${ }^{8}$ Bellvitge University Hospital, Rheumatology, Barcelona, Spain

Background: X-Ray sacroilitis is the cornerstone in the diagnosis of the ankylosing spondylitis (AS). It is clear that the presence of sacroiliitis is a specific lesion in long standing AS, but little evidence exists on the reliability of this image technique in early axial spondyloarthritis $(\operatorname{axSpA})$, which associates with reduced structural damage. This is relevant because some rheumatologists and pharmacological authorities feel more confident with the diagnosis of AS rather than with non radiographic axial spondyloarthritis (nr-axSpA) forms. On the other hand, according to various research studies, clinicians are subject to potential bias when interpreting radiographs, influenced by their pretest clinical judgment.

Objectives: The aim of this study is to determine the value of X-Ray sacroilitis in the early diagnosis of axSpA.

Methods: This study included 290 radiographs of the $\mathrm{SI}$ joints from patients of the Esperanza early spondyloarthritis cohort. Nine readers, blinded for the diagnosis, participated in the reliability exercise, all of them experienced rheumatologists and members of the Spanish spondiloarthritis working group (GRESSER). Patients with axSpa were classified as having AS if the radiographic criteria of the modified NY criteria (presence of radiographic changes in the SIJ of at least grade II bilaterally or at least grade III unilaterally) were fulfilled. The gold standard was the categorical opinion of at least five of the expert readers. For the statistical analysis, the Chi-square and Kappa tests were performed.

Results: The radiographic diagnosis, sensitivity, specificity, likelihood ratio, grade of agreement and mean $\mathrm{K}$ values compared to gold standard are showed in table 1. The concordance Kappa test was highly variable among the readers, ranging from fair to excellent. The agreement with the gold standard varied from 68 to $94 \%$ and the sensitivity and specifity, from $50-100 \%$ and $64-96 \%$, respectively. Additionally, the number of AS was 61, with an inter-reader variability rate of 31 to 138 . Larger discrepancies were observed when assessing sacroilitis grade 2 .

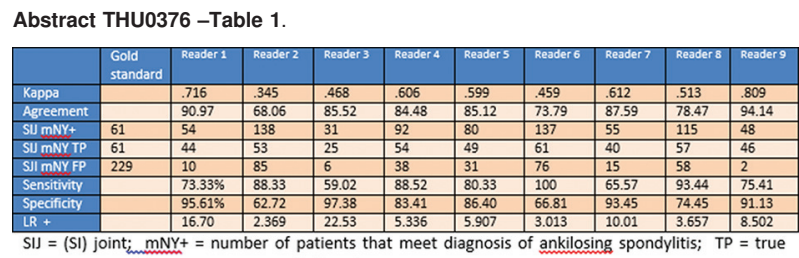

positives; $F P$ = false positives; $L R+=$ Likelihood ratio +

Conclusion: The diagnosis of AS in early axSpa is characterized by a marked variability. At least in doubtful cases, a second central evaluation performed by highly qualified experts should be advisable.

Disclosure of Interests: Eugenio de Miguel: None declared, Beatriz Joven-Ibáñez Speakers bureau: Celgene, Novartis, MSD, Pfizer, AbbVie, and Janssen, Eva Galindez: None declared, Claudia Urrego-Laurín: None declared, Maria Luz García-Vivar: None declared, Cristina Fernández-Carballido: None declared, Jose Francisco Garcia LLorente: None declared, María del Carmen Castro Villegas Paid instructor for: MSD, Abbvie, Pfizer, Janssen, Lilly, Roche, Carolina Tornero: None declared, Xavier Juanola-Roura: None declared

DOI: 10.1136/annrheumdis-2019-eular.7696

\section{THU0377 THE CARDIOVASCULAR ASSOCIATIONS WITH ENTHESITIS AND DACTYLITIS IN PATIENTS WITH SPONDYLOARTHRITIS: RESULTS FROM THE ASAS- COMOSPA STUDY}

Mohammad H. Derakhshan ${ }^{1}$, Nicola Goodson ${ }^{2}$, Jonathan Packham ${ }^{3}$, Raj Sengupta ${ }^{4}$, Anna Moltó ${ }^{5}$, Helena Marzo-Ortega ${ }^{6}$, Stefan Siebert ${ }^{\prime}$, On behalf of BRITSpA and the ASAS-COMOSPA investigators. ${ }^{1}$ University of Glasgow, Institute of Infection, Immunity and Inflammation, Glasgow, United Kingdom; ${ }^{2}$ University of Liverpool, Academic Rheumatology Department, Liverpool, United Kingdom; ${ }^{3}$ Keele University, Haywood Rheumatology Centre, Stoke on Trent, United Kingdom; ${ }^{4}$ Royal National Hospital for Rheumatic Diseases, Bath, United Kingdom; ${ }^{5}$ Hopital Cochin, Paris, France; ${ }^{6}$ University of Leeds, NIHR LBRC, Leeds, United Kingdom

Background: Enthesitis and dactylitis are considered characteristic inflammatory musculoskeletal manifestations of spondyloarthritis (SpA). These manifestations are usually assessed in the context of their assumed underlying specific condition rather than as distinct entities. Data from the ASAS-COMOSPA cohort have recently been shown that duration of SpA disease is associated with higher odds of hypertension particularly in axial $\mathrm{SpA}(1)$.

Objectives: To evaluate the possible associations of dactylitis and enthesitis phenotypes with cardiovascular comorbidities in a heterogeneous cohort of patients with SpA.

Methods: ASAS-COMOSPA is a global cross-sectional study assessing comorbidities in 3984 patients with SpA. History of enthesitis or dactylitis was based on self-report with confirmation using the medical records. Associations between dactylitis or enthesitis with hypertension, dyslipidaemia, diabetes, ischemic heart diseases (IHD) and stroke were analysed by separate logistic regression models unadjusted, adjusted for age and sex (models 1), and adjusted for age, sex and BMI (model 2).

Results: The data of 3905 participants were available for analysis. There were $1480(37.9 \%)$ with history of enthesitis and $611(15.6 \%)$ with dactylitis, while 1814 (46.5\%) had neither.

Presence of dactylitis was associated with hypertension in the univariable analysis [OR=1.68; $95 \% \mathrm{Cl}$ : $1.39-2.03]$. The association remained significant when adjusted for age and sex, but not following further adjustment for BMl (Table). Similarly, enthesitis was associated with hypertension in the univariable analysis [OR=1.36; $95 \% \mathrm{Cl}$ : 1.17-1.59], which remained after adjusted for age and sex, as well as after further adjustment for BMI (Table). Similar associations were seen for dyslipidaemia and dactylitis [OR=1.60; $95 \% \mathrm{Cl}: 1.29-1.98$ ] or enthesitis [OR=1.50; $95 \% \mathrm{Cl}: 1.26$ 1.77], with the association with dactylitis lost after further adjustment for BMI while the association with enthesitis remained significant (Table). While there were significant associations between dactylitis and diabetes [OR: $1.50(95 \% \mathrm{Cl}: 1.07-2.11)$ ], and between enthesitis and diabetes [OR=1.35; $95 \% \mathrm{Cl}: 1.02-1.78]$ in unadjusted models, no associations were 